\title{
Classification of advanced methods for evaluating neurotoxicity
}

\author{
Kyung-Seok Han ${ }^{1}$ · Dong Ho Woo ${ }^{2}$
}

Accepted: 5 August 2021 / Published online: 18 August 2021

(c) The Author(s) 2021

\begin{abstract}
Purpose of review As fields such as neurotoxicity evaluation and neuro-related drug research are increasing in popularity, there is a demand for the expansion of neurotoxicity research. Currently, neurotoxicity is assessed by measuring changes in weight and behavior. However, measurement of such changes does not allow the detection of subtle and inconspicuous neurotoxicity. In this review, methods for advancing neurotoxicity research are divided into molecule-, cell-, circuit-, and animal model-based methods, and the results of previous studies assessing neurotoxicity are provided and discussed.

Recent findings In coming decades, cooperation between universities, national research institutes, industrial research institutes, governments, and the private sector will become necessary when identifying alternative methods for neurotoxicity evaluation, which is a current goal related to improving neurotoxicity assessment and an appropriate approach to neurotoxicity prediction. Many methods for measuring neurotoxicity in the field of neuroscience have recently been reported. This paper classifies the supplementary and complementary experimental measures for evaluating neurotoxicity.
\end{abstract}

Keywords Neurotoxicity $\cdot$ Synapse $\cdot$ Ion channel $\cdot$ Synaptic plasticity $\cdot$ Electrophysiology $\cdot$ Imaging

\section{Introduction}

According to a global burden disease study, from 1990 to 2016, there was a $29.9 \%$ increase in years lived with disability (YLDs) for subjects with bipolar disorder (from 376.4 to 489.1 YLDs in thousands), a $65.6 \%$ increase for dementia (from 360.8 to 597.6 YLDs in thousands), a $13.6 \%$ increase for alcohol-related disorders (from 558.2 to 633.9 YLDs in thousands), a 36\% increase for schizophrenia (from 503.3 to 685.2 YLDs in thousands), a $30.5 \%$ increase for opioid use disorders (from 1256.2 to 1638.9 YLDs in thousands), a $30.8 \%$ increase for anxiety disorders (from 1341.7 to 1755.0 YLDs in thousands), a 27.2\% increase for migraine (from 1580.3 to 2010.1 YLDs in thousands), and a $27.0 \%$ increase for major depressive disorder (from 1726.2 to 2193.0 YLDs in thousands) (Collaborators, U.S.B.o.D. et al. 2018).

Kyung-Seok Han

kshan@ddongguk.ac.kr

Dong Ho Woo

dongho.woo@kitox.re.kr

1 Department of Medical Biotechnology, Dongguk UniversityGyeongju, 123 Dongdae-ro, Gyeongju, South Korea

2 Research Center for Convergence Toxicology, Korea Institute of Toxicology, Daejeon, South Korea
Neuromodulation technologies are required for the assessment of treatments and drugs administered for various diseases. Such technologies are used to improve cognition in stroke or dementia patients, aid recovery from mental illness, and rapidly assess the effects of drugs.

Current methods used to measure neurotoxicity involve assessing the effects of drugs on the central nervous system (CNS) by evaluating behaviors. However, behaviors represent many physiological functions and therefore cannot be used to assess specific neurotoxic effects. As many studies in neuroscience are being performed, various methods for measuring neurotoxicity are being developed. Systems biology, bioinformatics, and rapid assay technologies may be alternatives to the existing behavioral tests (Gibb 2008). Methods for assessing the risk of neurotoxicity are shifting from traditional animal toxicity tests to various mechanistic studies designed to clarify the toxicity mechanism and identify techniques for coping with the adverse effects of toxic substances (Krewski et al. 2009). In this paper, we present a classification system for various methods that may be used to assess neurotoxicity.

In neuroscience, the mechanisms underlying the connections between various circuits were established through the study of synapses. For example, the memory and learning processes can be explained by long-term and short-term 
synaptic plasticity (Bliss and Collingridge 1993; Buzsaki and Eidelberg 1982; Bear and Abraham 1996; Lee et al. 2007). $N$-methyl-D-aspartate receptors (NMDARs) (Bliss and Collingridge 1993; Abraham et al. 2019), $\alpha$-amino3-hydroxy-5-methyl-4-isoxazole propionic acid receptors (AMPARs) (Barria et al. 1997; Roche et al. 1996; Woo et al. 2012; Huganir and Nicoll 2013), and gamma-aminobutyric acid (GABA) receptors (GABARs) (Das et al. 2011; Lee et al. 2010) are synaptic channels related to synaptic plasticity. Standardized research methods should be used to evaluate synaptic activity within synaptic channels.

\section{Synapses as targets for assessing neurotoxicity}

The evaluation of drug safety requires measuring CNS, cardiovascular system, and respiratory system functions. In particular, current methods used for evaluating the safety of drugs in the CNS primarily involve behavior-based assessments. The behavioral tests commonly used for rodents are the open field test, which measures exploratory behavior and general activity, and the Morris water maze test, which assesses spatial learning and memory. Unfortunately, behavioral evaluations in the laboratory can be subjective and nonreproducible due to the characteristics of the person performing the experiment and various environmental factors, including housing conditions. Furthermore, behavior involves the integration of complex processes, including the actions of various molecules, synaptic activity, and a summation of various neural circuits; thus, behavioral results are nonspecific. Therefore, there is a need to specifically study each step in the behavior being assessed by separating the complex stages of the behavioral output. The first specific target could be the synapses that allow neurons to communicate with other neurons through the transmission of a chemical or electrical signal. In the field of neuroscience, identifying the cellular mechanism underlying synaptic modification helps to elucidate behavioral changes. Synapses contain various ion channels that regulate neuronal activity and synaptic plasticity, and they are directly linked to behavioral changes, so they could be considered principal targets for neurotoxicity assessments.

\section{Ion channels}

AMPARs and NMDARs are ionotropic glutamate receptors that regulate neuronal activity by mediating excitatory synaptic transmission in the brain. AMPAR- and NMDAR-mediated synaptic transmission triggers long-term changes in synaptic plasticity, leading to changes in behavior (Bredt and Nicoll 2003; Malinow and Malenka 2002; Newpher and Ehlers 2008). GABA, the major inhibitory neurotransmitter, reduces neuronal excitability throughout the nervous system, and
GABAA receptor-mediated neurotransmission is critical for various behavioral actions related to ethanol and is associated with anesthesia, sedation, hypnosis, and anxiolysis (Lobo and Harris 2008). The GABAA receptor has also been reported to be involved in drug addiction behavior, including nicotine dependence (Agrawal et al. 2008a), cannabis abuse (Agrawal et al. 2008b), cocaine addiction (Dixon et al. 2010), and heroin dependence (Enoch et al. 2010), in both human and animal studies. In addition, through the use of genetic, behavioral, and pharmacological techniques, it has been shown that a GABAA receptor subunit modulates anxiety- and depression-related behaviors (Smith and Rudolph 2012). The transient receptor potential (TRP) channel is involved in the nonspecific conductance of cations and is highly permeable to $\mathrm{Ca}^{2+}$. The activation of TRP channels is directly related to nociceptive transmission, mechanosensation, axonal guidance, and gastrointestinal sensation (Sadler and Stucky 2019; Ramsey et al. 2006; Yu et al. 2016). Measurement of currents flowing through channels in the synapse using electrophysiological methods can directly and specifically assess neurotoxicity under different conditions.

\section{Synaptic plasticity}

Various changes in behavior, including long-term potentiation (LTP) and long-term depression (LTD), most likely depend on synaptic plasticity, which can be mediated by trafficking or removal of AMPARs. Activity-dependent synaptic plasticity is induced at appropriate synapses during memory formation and is critical for information storage (Kandel and Schwartz 1982; Lynch and Baudry 1984; Korol et al. 1993; Morris and Frey 1997). NMDAR-dependent synaptic plasticity in hippocampal synapses is critically involved in hippocampus-dependent spatial learning and memory. The first studies of the role of LTP in memory formation demonstrated that the persistence of LTP is significantly correlated with the rate of learning and spatial memory ability over time (Barnes 1979; Barnes and McNaughton 1985). Synaptic plasticity is also involved in amygdala-dependent fear learning and memory. The fear-conditioning paradigm, which involves memory formation, induces a form of LTP in the amygdala (Rogan et al. 1997; Rogan and LeDoux 1995; McKernan and Shinnick-Gallagher 1997). Furthermore, several studies have suggested that changes in behavior caused by addictive drugs can be mediated by synaptic plasticity in the mesolimbic reward system (Kauer and Malenka 2007).

\section{Action potentials}

Action potentials (APs), which are generated by transient changes in the movement of $\mathrm{Na}^{+}$and $\mathrm{K}^{+}$ions across the neuronal membrane, are required for neural communication. APs 
contain information based on a diverse coding scheme. In motor neurons, the frequency or rate of APs determines the force exerted by a muscle during a voluntary contraction; this coding scheme is called the 'rate code'. The rate code model of neuronal communication through APs suggests that the rate of APs increases as the intensity of a stimulus increases (Stein et al. 2005; Gerstner et al. 1997; Adrian and Zotterman 1926). On the other hand, according to the 'temporal code' scheme, information is transmitted in the auditory, visual, and somatosensory systems via the precise timing of APs (Gerstner and Kistler 2002; Dayan and Abbott 2001). Several studies have shown that the temporal resolution of APs on the millisecond scale is critical for transmitting neural information (Eckmiller et al. 1990; Butts et al. 2007; Gollisch and Meister 2008). Another neural coding scheme for neuronal communication through APs is the 'synchrony code', in which APs are synchronously generated within less than a millisecond. Purkinje cells in the cerebellum synchronize their APs for information coding during behavior. A working hypothesis is that the synchronous APs of Purkinje cells regulate the activity of postsynaptic neurons, thereby transmitting information from the cerebellum (Gauck and Jaeger 2000; Bell and Grimm 1969; Person and Raman 2011; Han, et al. 2018). Measurement of APs using electrophysiological methods can be used to directly assess neurotoxicity related to cellular mechanisms and behaviors that are encoded by frequency, timing, or synchronicity of AP activity.

\section{High-throughput assays}

Methods for recording spikes (Kodandaramaiah 2018) and evaluating the activity of sodium channels (Zhang et al. 2020), potassium channels (Kutchinsky et al. 2003), chloride channels (Billet et al. 2017), and cation channels (McPate et al. 2014) through an automated patch-clamp technique are well established. However, such methods require professional-level quality control and can cost a considerable amount of money; thus, they are challenging to perform in small laboratories.

Microelectrode arrays (MEAs) are in vitro measurement devices used to measure the rhythmicity of heart cells. Such devices are relatively easy to use; thus, there is a demand for their use when assessing neuronal excitability (Malerba et al. 2018; Kizner et al. 2019; Taga et al. 2019). Human-derived stem cells are required for MEA-based research technology.

\section{In vivo assays}

Electroencephalography (EEG) is an electrophysiological method used to record fluctuations in ionic current voltages and, thus, to assess neuronal activity in vivo (Niedermeyer and Silva 2005). Even though the electrical activity of a single neuron cannot be detected, the summed activity of numerous neuronal populations can be measured by EEG. Generally, EEG has been used to assess neuronal activity in the context of assessing epilepsy, seizure disorders, and other conditions, including brain tumors, brain damage, brain inflammation, stroke, and sleep disorders. The advantages of EEG are its lower start-up cost compared to other techniques (Vespa et al. 1999), its high temporal resolution (Montoya-Martinez et al. 2021), and it does not require the use of radioligands (Yasuno et al. 2008). Furthermore, EEG can be performed simultaneously with neuroimaging techniques such as functional magnetic resonance imaging (fMRI) and positron emission tomography (PET). Therefore, the recording of electrical signals via EEG in vivo might be useful when assessing the association of neurotoxicity with various diseases.

\section{Imaging-based assays}

Imaging-based assays indirectly measure ionic movement based on membrane potential or ion concentration changes and provide more spatial information than that obtained from the patch-clamp technique. Voltage changes are measured by voltage-sensitive dyes that exhibit potential-dependent changes in their properties. Bis-trimethine oxonol (DiBAC ${ }_{4}$ (3)) has been applied in high-throughput screening and optimized for detecting steady-state rather than kinetic changes in potential (Yamada et al. 2001). FMP, another membrane potential dye, shows a high level of temporal resolution when measuring kinetic changes (Whiteaker et al. 2001). Fluorescence resonance energy transfer (FRET)-based assays are also widely used to measure membrane hyperpolarization or depolarization. Specific ion concentrations are measured with ion-specific probes, including Fura-2, Fluo3, and Fluo-4 as $\mathrm{Ca}^{2+}$ indicators (Kao et al. 1989; Minta et al. 1989), FluxOR and PBFI for $\mathrm{K}^{+}$ions (Beacham et al. 2010; Meuwis et al. 1995), and SBFI for $\mathrm{Na}^{+}$ions (Minta and Tsien 1989).

Various neurotransmitters, such as glutamate, dopamine, GABA, 5-HT, acetylcholine, and norepinephrine, (Sun et al. 2018 , 2020) can be monitored with sensors that provide high sensitivity and spatiotemporal resolution (Banerjee et al. 2020; Sun et al. 2018, 2020). The incorporation of nanomaterials, biomolecules, and polymers is helpful in the development of sensors for neurotransmitters. In addition, a voltammetry-based approach for electrochemical sensing has been recently developed for in vivo measurement.

\section{Cell-based toxicity assays}

In some cases, the cause of the neurological disease may be the death of nerve cells within the brain. Therefore, measurement of neuronal viability can be used to assess 
neurotoxicity. Prenatal exposure to lipopolysaccharide induces depression-like behavior by reducing the number of BrdU-positive cells, which are newly generated proliferating neuronal cells (Lin and Wang 2014) (Table 1).

It has been reported that neuronal differentiation is associated with neurodevelopmental toxicity. Class 3 betatubulin, a marker of neuronal differentiation, has been used to detect neuronal differentiation to determine whether 9-cis retinoic acid, methylmercury, and 22(R)-hydroxycholesterol affect the differentiation of NT/D1 cells with neuronal stem cells characteristics (Taylor et al. 2019).
The balance between neuronal proliferation and apoptosis, a form of programmed cell death, has an important effect on normal brain development. Therefore, toxic substances, which can be produced due to apoptosis, can affect normal brain morphology and function. The enzymatic activity of caspase-3/7 has been used to assess apoptosis (Druwe et al. 2015), whereas $\beta$-tubulin type III has been used as a molecular marker of the migration of human Ntera2 (NT2) cells (Stern et al. 2014). Disorganizations within the ventricular zone, the neuroependyma, radial glial scaffolds, or tangential fibers have been used

Table 1 Classification of the advanced methods for assessing neurotoxicity

\begin{tabular}{|c|c|c|c|}
\hline Method & Target and level & Measure & References \\
\hline \multirow[t]{6}{*}{ Patch-clamp recording } & \multirow[t]{4}{*}{ Ion channels } & AMPAR-mediated currents & $\begin{array}{l}\text { Barria et al. 1997; Roche et al. 1996; } \\
\text { Woo et al. 2012; Huganir et al. } 1996\end{array}$ \\
\hline & & NMDAR-mediated currents & $\begin{array}{l}\text { Bliss and Collingridge 1993; Abraham } \\
\text { et al. } 2019\end{array}$ \\
\hline & & GABAR-mediated currents & Das et al. 2011; Lee et al. 2010 \\
\hline & & Cation channels-mediated current & $\begin{array}{l}\text { Sadler and Stucky 2019; Ramsey et al. } \\
\text { 2006; Yu et al. } 2016\end{array}$ \\
\hline & Neuronal excitability & APs in response to current steps & $\begin{array}{l}\text { Eckmiller et al. 1990; Butts et al. 2007; } \\
\text { Gollisch and Meister 2008; Gauck and } \\
\text { Jaeger 2000; Bell and Grimm 1969; } \\
\text { Person and Raman 2011; Han et al. } \\
2018\end{array}$ \\
\hline & Synaptic plasticity & $\begin{array}{l}\text { Short-term plasticity } \\
\text { Long-term plasticity }\end{array}$ & $\begin{array}{l}\text { Bliss and Collingridge 1993; Buzsaki } \\
\text { and Eidelberg 1982; Bear and Abra- } \\
\text { ham 1996; Lee et al. } 2007\end{array}$ \\
\hline \multirow[t]{3}{*}{ High-throughput assays } & MEA & & $\begin{array}{l}\text { Malerba et al. 2018; Kizner et al. 2019; } \\
\text { Taga et al. } 2019\end{array}$ \\
\hline & \multicolumn{2}{|c|}{ Automated patch-clamp recordings } & $\begin{array}{l}\text { Kodandaramaiah 2018; Zhang et al. } \\
\text { 2020; Billet et al. 2017; McPate et al. } \\
2014\end{array}$ \\
\hline & \multicolumn{2}{|l|}{$\mathrm{Ca}^{2+}$ levels } & Minta and Tsien 1989; Minta et al. 1989 \\
\hline \multirow[t]{2}{*}{ Imaging-based assays } & \multicolumn{2}{|l|}{ Voltage } & $\begin{array}{l}\text { Yamada et al. 2001; Whiteaker et al. } \\
2001\end{array}$ \\
\hline & \multicolumn{2}{|l|}{ Neurotransmitter levels } & $\begin{array}{l}\text { Banerjee et al. 2020; Sun et al. 2018, } \\
2020\end{array}$ \\
\hline In vivo assays & \multicolumn{2}{|l|}{ EEG } & $\begin{array}{l}\text { Niedermeyer and Silva 2005; Vespa } \\
\text { et al. 1999; Montoya-Martinez et al. } \\
\text { 2021; Yasuno et al. } 2008\end{array}$ \\
\hline \multirow{9}{*}{$\begin{array}{l}\text { Western blotting, ELISA, } \\
\text { immunocytochemistry, and } \\
\text { immunohistochemistry }\end{array}$} & \multirow[t]{2}{*}{ Cells } & Proliferation & Lin and Wang 2014 \\
\hline & & Differentiation & Taylor et al. 2019 \\
\hline & \multirow[t]{4}{*}{ Neural cell circuits } & Migration & Stern et al. 2014; Moroni et al. 2011 \\
\hline & & Apoptosis & Druwe et al. 2015 \\
\hline & & Neurite growth & $\begin{array}{l}\text { Akane et al. 2014; Powell et al. 1986; } \\
\text { Parran et al. } 2003\end{array}$ \\
\hline & & Synaptogenesis & Brat and Brimijoin 1992 \\
\hline & \multirow{3}{*}{$\begin{array}{l}\text { Neural circuits } \\
\text { Animal models }\end{array}$} & Myelination & Suminaite et al. 2019; Dutta et al. 2018 \\
\hline & & Chemical induced-model & $\begin{array}{l}\text { Torkildsen et al. 2008; Zeng et al. 2018; } \\
\text { Schneider and Przewlocki } 2005\end{array}$ \\
\hline & & $\begin{array}{l}\text { Genetic models (transgenic and knockout } \\
\text { models) }\end{array}$ & $\begin{array}{l}\text { Borchelt et al. 1997; Holcomb et al. } \\
\text { 1998; Dawson et al. } 2010\end{array}$ \\
\hline
\end{tabular}


as markers of neuronal migration defects (Moroni et al. 2011).

\section{Neural circuit-based toxicity assays}

Neural circuits can be assessed by measuring neurite growth, synaptogenesis, and myelination (Brat and Brimijoin 1992). Glycidol exposure increases the gene expression of Kl, Igf2, and Igfbp2 in the corpus callosum to promote myelination, while Efnb3, Tnc, and Cd44 gene expression increases in the cingulate cortex promote neurite growth (Akane et al. 2014). The safety of galactose (Powell et al. 1986) and methylmercury (Parran et al. 2003) has been assessed by measuring neurite growth. The thickness of myelin around axons and the nodal gap length can be determined by measuring the expression of myelin-mediated molecules such as pan-sodium and Caspr1 (Suminaite et al. 2019; Dutta et al. 2018).

\section{Animal model-based toxicity assays}

Cuprizone injection has been used in the establishment of an animal model of multiple sclerosis through the induction of demyelination (Torkildsen et al. 2008). Injections of 6-hydroxydopamine, 1-methyl-4-phenyl-1,2,3,6-tetrahydropyridine, paraquat, and rotenone have been used to generate animal models of Parkinson's disease through induction of dopaminergic neuron death in the substantia nigra compacta (Zeng et al. 2018). In addition, valproic acid injection has been used to establish a model of autism spectrum disorder, a psychiatric disorder (Schneider and Przewlocki 2005).

Apolipoprotein E4 (apoE4) is very strongly associated with Alzheimer's disease. Expression of both mutant presenilin 1 (PS1) and mutant amyloid precursor protein (APP) is associated with the deposition of amyloid aggregates and Alzheimer's disease-like behaviors (Borchelt et al. 1997; Holcomb et al. 1998). Mutations in LRRK2, alpha-synuclein, parkin, DJ-1, and PINK1 are strongly related to Parkinson's disease (Dawson et al. 2010).

\section{Conclusion}

In this review, we suggest that neurotoxicity should be assessed by analyzing a variety of measures, including measurement of parameters related to synapses, ion channels, synaptic plasticity, and APs, as well as the application of electrophysiological and imaging techniques in cell, circuit, and animal models. To date, standardized criteria for measuring neurotoxicity have not been fully established. In the future, there is a need to develop a classification system and standardized methods for use in neurotoxicity research. It is also necessary for government-funded research institutes to propose an active research methodology to obtain research results that follow the regulatory direction of the government. Cooperation between governments, industry, institutes, and universities is necessary for the further development of technology for assessing neurotoxicity.

Acknowledgements This work was supported by grant 20182MFDS423 and 21182MFDS356 from the Ministry of Food and Drug Safety in 2021, the 2020 Dongguk University Research Fund, and the National Research Foundation of Korea (NRF) grant funded by the Korean government (MSIT) (NRF-2020R1G1A1103025).

Author contributions $\mathrm{KSH}$ contributed to ideating the concept and wrote the part related to electrophysiology in the manuscript. DHW conceived and wrote the manuscript.

\section{Declarations}

Conflict of interest D.H. Woo declares that he has no conflict of interest. K.S. Han declares that he has no conflict of interest.

Ethical approval The article does not have any studies with humans and animals performed by the authors.

Human and animal rights This article does not contain any studies with human participants or animals performed by any of the authors.

Open Access This article is licensed under a Creative Commons Attribution 4.0 International License, which permits use, sharing, adaptation, distribution and reproduction in any medium or format, as long as you give appropriate credit to the original author(s) and the source, provide a link to the Creative Commons licence, and indicate if changes were made. The images or other third party material in this article are included in the article's Creative Commons licence, unless indicated otherwise in a credit line to the material. If material is not included in the article's Creative Commons licence and your intended use is not permitted by statutory regulation or exceeds the permitted use, you will need to obtain permission directly from the copyright holder. To view a copy of this licence, visit http://creativecommons.org/licenses/by/4.0/.

\section{References}

Abraham WC, Jones OD, Glanzman DL (2019) Is plasticity of synapses the mechanism of long-term memory storage? NPJ Sci Learn 4:9

Adrian ED, Zotterman Y (1926) The impulses produced by sensory nerve-endings: Part II. The response of a Single End-Organ. J Physiol 61:151-171

Agrawal A et al (2008a) Gamma-aminobutyric acid receptor genes and nicotine dependence: evidence for association from a casecontrol study. Addiction 103:1027-1038

Agrawal A et al (2008b) Autosomal linkage analysis for cannabis use behaviors in Australian adults. Drug Alcohol Depend 98:185-190

Akane $\mathrm{H}$ et al (2014) Gene expression profile of brain regions reflecting aberrations in nervous system development targeting the process of neurite extension of rat offspring exposed developmentally to glycidol. J Appl Toxicol 34:1389-1399

Banerjee S, McCracken S, Hossain MF, Slaughter G (2020) Electrochemical detection of neurotransmitters. Biosensors (Basel) 10 
Barnes CA (1979) Memory deficits associated with senescence: a neurophysiological and behavioral study in the rat. J Comp Physiol Psychol 93:74-104

Barnes CA, McNaughton BL (1985) An age comparison of the rates of acquisition and forgetting of spatial information in relation to long-term enhancement of hippocampal synapses. Behav Neurosci 99:1040-1048

Barria A, Muller D, Derkach V, Griffith LC, Soderling TR (1997) Regulatory phosphorylation of AMPA-type glutamate receptors by CaM-KII during long-term potentiation. Science 276:2042-2045

Beacham DW, Blackmer TMOG, Hanson GT (2010) Cell-based potassium ion channel screening using the FluxOR assay. J Biomol Screen 15:441-446

Bear MF, Abraham WC (1996) Long-term depression in hippocampus. Annu Rev Neurosci 19:437-462

Bell CC, Grimm RJ (1969) Discharge properties of Purkinje cells recorded on single and double microelectrodes. J Neurophysiol 32:1044-1055

Billet A, Froux L, Hanrahan JW, Becq F (2017) Development of automated patch clamp technique to investigate CFTR chloride channel function. Front Pharmacol 8:195

Bliss TV, Collingridge GL (1993) A synaptic model of memory: longterm potentiation in the hippocampus. Nature 361:31-39

Borchelt DR et al (1997) Accelerated amyloid deposition in the brains of transgenic mice coexpressing mutant presenilin 1 and amyloid precursor proteins. Neuron 19:939-945

Brat DJ, Brimijoin S (1992) A paradigm for examining toxicant effects on viability, structure, and axonal transport of neurons in culture. Mol Neurobiol 6:125-135

Bredt DS, Nicoll RA (2003) AMPA receptor trafficking at excitatory synapses. Neuron 40:361-379

Butts DA et al (2007) Temporal precision in the neural code and the timescales of natural vision. Nature 449:92-95

Buzsaki G, Eidelberg E (1982) Direct afferent excitation and longterm potentiation of hippocampal interneurons. J Neurophysiol 48:597-607

Collaborators, U.S.B.o.D. et al (2018) The State of US Health, 19902016: Burden of Diseases, Injuries, and Risk Factors Among US States. JAMA 319:1444-1472

Das $S$ et al (2011) Plasticity of local GABAergic interneurons drives olfactory habituation. Proc Natl Acad Sci USA 108:E646-654

Dawson TM, Ko HS, Dawson VL (2010) Genetic animal models of Parkinson's disease. Neuron 66:646-661

Dayan P, Abbott LF (2001) Theoretical neuroscience : computational and mathematical modeling of neural systems. Massachusetts Institute of Technology Press, Cambridge

Dixon CI et al (2010) Cocaine effects on mouse incentive-learning and human addiction are linked to alpha2 subunit-containing GABAA receptors. Proc Natl Acad Sci USA 107:2289-2294

Druwe I, Freudenrich TM, Wallace K, Shafer TJ, Mundy WR (2015) Sensitivity of neuroprogenitor cells to chemical-induced apoptosis using a multiplexed assay suitable for high-throughput screening. Toxicology 333:14-24

Dutta DJ et al (2018) Regulation of myelin structure and conduction velocity by perinodal astrocytes. Proc Natl Acad Sci USA 115:11832-11837

Eckmiller R, Hartmann G, Hauske G (1990) Parallel processing in neural systems and computers. North-Holland; Distributors for the U.S. and Canada, Elsevier Science Pub. Co., Amsterdam; New York

Enoch MA et al (2010) The influence of GABRA2, childhood trauma, and their interaction on alcohol, heroin, and cocaine dependence. Biol Psychiatry 67:20-27

Gauck V, Jaeger D (2000) The control of rate and timing of spikes in the deep cerebellar nuclei by inhibition. J Neurosci 20:3006-3016
Gerstner W, Kistler WM (2002) Spiking neuron models : single neurons, populations, plasticity. Cambridge University Press, Cambridge, New York

Gerstner W, Kreiter AK, Markram H, Herz AV (1997) Neural codes: firing rates and beyond. Proc Natl Acad Sci U S A 94:12740-12741

Gibb S (2008) Toxicity testing in the 21st century: a vision and a strategy. Reprod Toxicol 25:136-138

Gollisch T, Meister M (2008) Rapid neural coding in the retina with relative spike latencies. Science 319:1108-1111

Han KS et al (2018) Ephaptic Coupling Promotes Synchronous Firing of Cerebellar Purkinje Cells. Neuron 100:564-578563

Holcomb L et al (1998) Accelerated Alzheimer-type phenotype in transgenic mice carrying both mutant amyloid precursor protein and presenilin 1 transgenes. Nat Med 4:97-100

Huganir RL, Nicoll RA (2013) AMPARs and synaptic plasticity: the last 25 years. Neuron 80:704-717

Kandel ER, Schwartz JH (1982) Molecular biology of learning: modulation of transmitter release. Science 218:433-443

Kao JP, Harootunian AT, Tsien RY (1989) Photochemically generated cytosolic calcium pulses and their detection by fluo-3. J Biol Chem 264:8179-8184

Kauer JA, Malenka RC (2007) Synaptic plasticity and addiction. Nat Rev Neurosci 8:844-858

Kizner V, Fischer S, Naujock M (2019) Multielectrode array (MEA)based detection of spontaneous network activity in human iPSCderived cortical neurons. Methods Mol Biol 1994:209-216

Kodandaramaiah SB et al (2018) Multi-neuron intracellular recording in vivo via interacting autopatching robots. Elife 7:e24656

Korol DL, Abel TW, Church LT, Barnes CA, McNaughton BL (1993) Hippocampal synaptic enhancement and spatial learning in the Morris swim task. Hippocampus 3:127-132

Krewski D, Andersen ME, Mantus E, Zeise L (2009) Toxicity testing in the 21st century: implications for human health risk assessment. Risk Anal 29:474-479

Kutchinsky J et al (2003) Characterization of potassium channel modulators with QPatch automated patch-clamp technology: system characteristics and performance. Assay Drug Dev Technol 1:685-693

Lee CJ et al (2007) Astrocytic control of synaptic NMDA receptors. J Physiol 581:1057-1081

Lee $\mathrm{S}$ et al (2010) Channel-mediated tonic GABA release from glia. Science 330:790-796

Lin YL, Wang S (2014) Prenatal lipopolysaccharide exposure increases depression-like behaviors and reduces hippocampal neurogenesis in adult rats. Behav Brain Res 259:24-34

Lobo IA, Harris RA (2008) GABA(A) receptors and alcohol. Pharmacol Biochem Behav 90:90-94

Lynch G, Baudry M (1984) The biochemistry of memory: a new and specific hypothesis. Science 224:1057-1063

Malerba M, Amin H, Angotzi GN, Maccione A, Berdondini L (2018) Fabrication of multielectrode arrays for neurobiology applications. Methods Mol Biol 1771:147-157

Malinow R, Malenka RC (2002) AMPA receptor trafficking and synaptic plasticity. Annu Rev Neurosci 25:103-126

McKernan MG, Shinnick-Gallagher P (1997) Fear conditioning induces a lasting potentiation of synaptic currents in vitro. Nature 390:607-611

McPate M et al (2014) The development of automated patch clamp assays for canonical transient receptor potential channels TRPC3, 6, and 7. Assay Drug Dev Technol 12:282-292

Meuwis K, Boens N, De Schryver FC, Gallay J, Vincent M (1995) Photophysics of the fluorescent $\mathrm{K}+$ indicator PBFI. Biophys J 68:2469-2473

Minta A, Tsien RY (1989) Fluorescent indicators for cytosolic sodium. J Biol Chem 264:19449-19457 
Minta A, Kao JP, Tsien RY (1989) Fluorescent indicators for cytosolic calcium based on rhodamine and fluorescein chromophores. J Biol Chem 264:8171-8178

Montoya-Martinez J, Vanthornhout J, Bertrand A, Francart T (2021) Effect of number and placement of EEG electrodes on measurement of neural tracking of speech. PLoS ONE 16:e0246769

Moroni RF et al (2011) Development of cortical malformations in BCNU-treated rat, model of cortical dysplasia. Neuroscience 175:380-393

Morris RG, Frey U (1997) Hippocampal synaptic plasticity: role in spatial learning or the automatic recording of attended experience? Philos Trans R Soc Lond B Biol Sci 352:1489-1503

Newpher TM, Ehlers MD (2008) Glutamate receptor dynamics in dendritic microdomains. Neuron 58:472-497

Niedermeyer E, Lopes da Silva FH (2005) Electroencephalography: basic principles, clinical applications, and related fields, Edn. 5th. Lippincott Williams \& Wilkins, Philadelphia

Parran DK, Barone S Jr, Mundy WR (2003) Methylmercury decreases NGF-induced TrkA autophosphorylation and neurite outgrowth in PC12 cells. Brain Res Dev Brain Res 141:71-81

Person AL, Raman IM (2011) Purkinje neuron synchrony elicits timelocked spiking in the cerebellar nuclei. Nature 481:502-505

Powell HC, Longo FM, LeBeau JM, Myers RR (1986) Abnormal nerve regeneration in galactose neuropathy. J Neuropathol Exp Neurol 45:151-160

Ramsey IS, Delling M, Clapham DE (2006) An introduction to TRP channels. Annu Rev Physiol 68:619-647

Roche KW, O’Brien RJ, Mammen AL, Bernhardt J, Huganir RL (1996) Characterization of multiple phosphorylation sites on the AMPA receptor GluR1 subunit. Neuron 16:1179-1188

Rogan MT, LeDoux JE (1995) LTP is accompanied by commensurate enhancement of auditory-evoked responses in a fear conditioning circuit. Neuron 15:127-136

Rogan MT, Staubli UV, LeDoux JE (1997) Fear conditioning induces associative long-term potentiation in the amygdala. Nature 390:604-607

Sadler KE, Stucky CL (2019) Neuronal transient receptor potential (TRP) channels and noxious sensory detection in sickle cell disease. Neurosci Lett 694:184-191

Schneider T, Przewlocki R (2005) Behavioral alterations in rats prenatally exposed to valproic acid: animal model of autism. Neuropsychopharmacology 30:80-89

Smith KS, Rudolph U (2012) Anxiety and depression: mouse genetics and pharmacological approaches to the role of $\operatorname{GABA}(\mathrm{A})$ receptor subtypes. Neuropharmacology 62:54-62

Stein RB, Gossen ER, Jones KE (2005) Neuronal variability: noise or part of the signal? Nat Rev Neurosci 6:389-397

Stern M, Gierse A, Tan S, Bicker G (2014) Human Ntera2 cells as a predictive in vitro test system for developmental neurotoxicity. Arch Toxicol 88:127-136
Suminaite D, Lyons DA, Livesey MR (2019) Myelinated axon physiology and regulation of neural circuit function. Glia 67:2050-2062

Sun F et al (2018) A genetically encoded fluorescent sensor enables rapid and specific detection of dopamine in flies, fish, and mice. Cell 174:481-496e419

Sun F et al (2020) Next-generation GRAB sensors for monitoring dopaminergic activity in vivo. Nat Methods 17:1156-1166

Taga A et al (2019) Role of human-induced pluripotent stem cellderived spinal cord astrocytes in the functional maturation of motor neurons in a multielectrode array system. Stem Cells Transl Med 8:1272-1285

Taylor MA, Kan HL, Gollapudi BB, Marty MS (2019) An in vitro developmental neurotoxicity screening assay for retinoic acidinduced neuronal differentiation using the human NT2/D1 cell line. Neurotoxicology 73:258-264

Torkildsen O, Brunborg LA, Myhr KM, Bo L (2008) The cuprizone model for demyelination. Acta Neurol Scand Suppl 188:72-76

Vespa PM, Nenov V, Nuwer MR (1999) Continuous EEG monitoring in the intensive care unit: early findings and clinical efficacy. $\mathbf{J}$ Clin Neurophysiol 16:1-13

Whiteaker KL et al (2001) Validation of FLIPR membrane potential dye for high throughput screening of potassium channel modulators. J Biomol Screen 6:305-312

Woo DH et al (2012) TREK-1 and Best1 channels mediate fast and slow glutamate release in astrocytes upon GPCR activation. Cell 151:25-40

Yamada A et al (2001) Usefulness and limitation of DiBAC4(3), a voltage-sensitive fluorescent dye, for the measurement of membrane potentials regulated by recombinant large conductance $\mathrm{Ca} 2+$-activated $\mathrm{K}+$ channels in HEK293 cells. Jpn J Pharmacol $86: 342-350$

Yasuno $\mathrm{F}$ et al (2008) The PET radioligand [11C]MePPEP binds reversibly and with high specific signal to cannabinoid CB1 receptors in nonhuman primate brain. Neuropsychopharmacology 33:259-269

Yu X, Yu M, Liu Y, Yu S (2016) TRP channel functions in the gastrointestinal tract. Semin Immunopathol 38:385-396

Zeng XS, Geng WS, Jia JJ (2018) Neurotoxin-induced animal models of Parkinson disease: pathogenic mechanism and assessment. ASN Neuro 10:1759091418777438

Zhang $\mathrm{H}$ et al (2020) Correlation of optical and automated patch clamp electrophysiology for identification of NaV1.7 inhibitors. SLAS Discov 25:434-446

Publisher's Note Springer Nature remains neutral with regard to jurisdictional claims in published maps and institutional affiliations. 